\title{
Formation of GFAP Cytoplasmic Inclusions in Astrocytes and Their Disaggregation by $\alpha \mathrm{B}$-Crystallin
}

\author{
Yutaka Koyama and James E. Goldman \\ From the Department of Pathology and the Center for \\ Neurobiology and Behavior, Columbia University College of \\ Physicians and Surgeons, New York, New York
}

In several neuropathological conditions, $\alpha \mathrm{B}$-crystallin and glial fibrillary acidic protein (GFAP) accumulate and form cytoplasmic inclusions in astrocytes. To explore the pathogenesis of the inclusions and the possible functions of the accumulated $\alpha B$-crystallin, GFAP and $\alpha B$-crystallin were overexpressed in cultured astrocytes by transient transfection. Human GFAP formed filamentous, cytoplasmic inclusions in mouse astrocytes, NIH3T3 cells, rat $\mathrm{C} 6$ glioma cells, and human U251 glioma cells. These human GFAP inclusions did not contain the endogenous vimentin or $\beta$-tubulin, and the intermediate filament and microtubular networks of the transfected cells appeared normal. $\alpha$ B-crystallin and hsp25 were associated with the GFAP inclusions. Increasing intracellular $\alpha B$-crystallin levels using recombinant adenoviruses, either before or after GFAP inclusions were formed, decreased the number of inclusion-bearing astrocytes and converted the human GFAP from an inclusion to a spread, filamentous form. These results suggest that $\alpha B$-crystallin reorganizes abnormal intermediate filament aggregates into the normal filamentous network. (Am J Patbol 1999, 154:1563-1572)

$\alpha \mathrm{B}$-crystallin, a structural component of the vertebrate lens, belongs to a family of small heat shock proteins (hsps). $\alpha$ B-crystallin is expressed constitutively at high levels in tissues such as cardiac and skeletal muscle and kidney ${ }^{1-3}$ but is inducible in many cell types by a variety of physiological stresses. ${ }^{4-6} \alpha \mathrm{B}$-crystallin prevents heatinduced aggregation of protein molecules in vitro ${ }^{7}$ and protects cells from damage caused by thermal and osmotic stresses. ${ }^{4,8,9}$ The mechanism(s) by which $\alpha \mathrm{B}$-crystallin exerts protective effects is not clear, although interactions with cytoskeletal proteins has been suggested to be important. ${ }^{10}$ For example, $\alpha$ B-crystallin stabilizes filamentous actin organization in glioma cells. ${ }^{8}$ In vitro, the association of $\alpha \mathrm{B}$-crystallin with F-actin prevents depolymerization. ${ }^{11}$ With respect to intermediate filaments (IFs), interactions between $\alpha \mathrm{B}$-crystallin and IFs have been noted in muscle, lens, and astrocytes. ${ }^{12-14}$ In vitro, $\alpha \mathrm{B}$ crystallin inhibits the polymerization of IFs, ${ }^{13}$ but whether this small hsp plays any role in the polymerization or organization of IFs in situ is unknown.

In a number of disorders, IFs form abnormal cytoplasmic aggregates, such as the Mallory bodies of hepatic cirrhosis, ${ }^{15}$ Lewy bodies of Parkinson disease, ${ }^{16}$ and Rosenthal fibers (RFs $)^{17-21}$ of Alexander disease, chronic glial scars, and low-grade, fibrillary astrocytomas. All of these IF inclusions also contain $\alpha \mathrm{B}$-crystallin, ${ }^{1,22,23}$ suggesting that there is some affinity between the proteins or that cells up-regulate small hsps in response to filament pathology. The latter idea is consistent with recent findings in transgenic mice that express the human GFAP (hGFAP) gene regulated by its own promoter. ${ }^{24}$ Astrocytes of these mice become hypertrophic and develop cytoplasmic inclusions similar or identical to RFs. Levels of the endogenous $\alpha \mathrm{B}$-crystallin and hsp27 mRNA are elevated, although levels of hsp70 mRNA remain normal in these brains, suggesting that the accumulation of IFs somehow induces a cellular stress reponse specific to small hsps. Furthermore, astrocytes cultured from the brains of the transgenic mice formed RFs without additional stress conditions, ${ }^{25}$ suggesting that overexpression of hGFAP is sufficient to induce the IF-containing inclusions in mouse astrocytes.

In this study, we explore the generation of IF inclusions and show that hGFAP transfected into mouse astrocytes forms inclusions separate from the endogenous IF network. In addition, to examine the effects of $\alpha \mathrm{B}$-crystallin on such inclusions, we introduced $\alpha \mathrm{B}$-crystallin into inclusion-bearing astrocytes. However, rather than forming RFs, the $\alpha$ B-crystallin acted to disperse the GFAP in the inclusions into the normal filamentous array. Thus, astrocytes may up-regulate small hsps as a response to abnormal IF organization in an attempt to restore the normal IF network.

\footnotetext{
Supported by NIH grant EY-09331 to J.E. Goldman.

Accepted for publication February 3, 1999

Y. Koyama's present address: Department of Pharmacology, Faculty of Pharmaceutical Sciences, Osaka University, 1-6 Yamada-Oka Suita, 565 Japan.

Address reprint requests to Dr. J.E. Goldman, Department of Pathology, Columbia University College of Physicians and Surgeons, 630W, 168th Streey, New York, NY 10032. E-mail:jeg5@columbia.edu.
} 


\section{Materials and Methods}

\section{Cell culture}

Astrocyte cultures were prepared from forebrains of 1 - to 2-day-old C57BL mice according to previously described methods. ${ }^{6}$ Dissociated cells were seeded on $75-\mathrm{cm}^{2}$ culture flasks at $2 \times 10^{5}$ cells $/ \mathrm{cm}^{2}$ and cultured in Eagle's minimal essential medium (MEM) supplemented with 5\% fetal calf serum (FCS), $100 \mathrm{U} / \mathrm{ml}$ penicillin G, $100 \mu \mathrm{g} / \mathrm{ml}$ streptomycin, $0.25 \mu \mathrm{g} / \mathrm{ml}$ amphotericin B, and $0.5 \% \mathrm{D}$ glucose. After cells reached confluence ( $\sim 10$ days), the small process-bearing oligodendrocyte progenitor cells and the microglia were removed by rotatory shaking. The remaining monolayer of astrocytes were used 12 to 24 days after initial seeding. Rat C6 glioma and human U251 astrocytoma lines were cultured in Dulbecco's MEM (DMEM) supplemented with 10\% FCS. NIH3T3 cells were cultured in DMEM supplemented with $5 \%$ calf serum.

\section{Expression Vectors}

An expression vector for hGFAP, RSVi-hGF, and the parent plasmid pRSVi-HindIII were generous gifts from Dr. Ron Liem (Columbia University, New York, NY). The HindIII cloning site in pRSVi-HindIII positions at the $3^{\prime}$ flanking region of the RSV long-term repeat. RSVi-hGF has a full-length protein-encoding region of human GFAP cDNA at the HindIII site in pRSVi-HindIII. ${ }^{26}$ An expression vector for mouse GFAP, RSVi-mGF, was constructed from a full-length protein-encoding region of mouse GFAP cDNA, which was obtained as a BamHI fragment of mouse GFAP cDNA clone, pGfa-mGfa2 (a gift from Dr. M. Brenner, National Institutes of Health, Bethesda, MD). The BamHI fragment was blunt-ended by T4 DNA polymerase and ligated to HindIII linkers. After the ligated linkers were digested by HindIII, the mouse GFAP fragment was subcloned into the HindIII site of pRSVi-HindIII to make RSVi-mGF. An expression vector for $E$. coli $\beta$-galactosidase ( $\beta$-Gal), pSV $\beta$-Gal, was purchased from Promega (Madison, $\mathrm{WI}$ ).

Recombinant adenovirus vectors carrying the rat $\alpha \mathrm{B}$ crystallin cDNA in the sense orientation or the $\beta$-Gal gene ( $\alpha$ BSAD and $\beta$-GalAD, gifts from Drs. Jody Martin and Wolfgang Dillman, University of California, San Diego, San Diego, CA) were described previously. ${ }^{27}$ In each vector, the transgene is driven by the CMV promoter/enhancer and flanked by an SV40 polyadenylation signal. Amplification, purification, and titration of these vectors were performed according to previously described methods. ${ }^{27}$

\section{Transfection with Vectors}

One day before transfection, cultured cells were trypsinized and plated on glass coverslips (12-mm diameter) coated with $20 \mu \mathrm{g} / \mathrm{ml}$ poly-L-lysine in 24-well culture plates. The cell density was $0.5 \times 10^{5}$ cells/well for mouse astrocytes and $0.25 \times 10^{5}$ cells/well for NIH3T3, C6, and U251 cells. Transfections were performed using a polyamine transfection reagent (TransIT LT-1, PanVera,
Madison, WI) according to the manufacturer's protocol. In most experiments, $1 \mu \mathrm{g}$ of GFAP expression vectors was used for each culture well. The polyamine reagent was diluted with OptiMEM (Gibco, Gaithersburg, MD) at $1: 10$, and the vectors were mixed with the diluted polyamine solution. After cells were rinsed with OptiMEM twice, $30 \mu \mathrm{l}$ of the DNA/polyamine mixture was added to each well filled with $270 \mu$ l of OptiMEM. Cells were incubated for 8 hours at $37^{\circ} \mathrm{C}$, and then the medium was changed to the respective growth medium. In the transfections of U251 with the hGFAP vector and of mouse astrocytes with the mouse GFAP vector, where endogenous GFAP prevents an immunohistochemical detection of vector-derived GFAP, co-transfection with the GFAP vectors and $\mathrm{pSV} \beta$-Gal at a 1:0.4 ratio was performed to distinguish the transfected cells.

\section{Infections with Adenovirus Vectors}

Astrocytes grown on coverslips in 24-well plates were infected with recombinant adenovirus vectors at a multiplicity of infection of 20. Purified adenoviral vectors were diluted in Eagle's MEM supplemented with 2\% FBS and astrocytes incubated in $200 \mu \mathrm{l}$ for 45 minutes at room temperature. After incubation, $800 \mu$ of MEM containing $10 \%$ FBS was added to the well. On the following day, the virus-containing medium was changed to the growth medium. We have found that $30 \%$ to $50 \%$ of cultured astrocytes expressed the transgene product after the adenovirus infection, and the transgene protein products remained at high levels for at least 6 weeks (MW Head, L Hurwitz, KB Kegel, and JE Goldman, submitted).

\section{Immunocytochemistry}

Two to fourteen days after transfection with GFAP expression vectors, cells were fixed with $3 \%$ paraformaldehyde in phosphate-buffered saline (PBS) for 30 minutes and permeabilized by $0.2 \%$ Nonidet P-40 (NP-40) in PBS for 7 minutes. In experiments to show accumulation of $\alpha \mathrm{B}$ crystallin and hsp25 in cytoskeletal components, cells were treated first with PBS containing 0.2\% NP-40, 5 $\mathrm{mmol} / \mathrm{L} \mathrm{MgCl}_{2}$, and $3 \mathrm{mmol} / \mathrm{L}$ EGTA for 2 minutes before paraformaldehyde fixation. Cells transfected with the hGFAP vector were selectively labeled by a hGFAP-specific mouse monoclonal antibody (SMI21, Sternberger Monoclonals, Baltimore, MD), which does not recognize mouse GFAP. The hGFAP-specific antibody was diluted in PBS containing 5\% goat serum and $0.01 \%$ NP-40 (1:1000 dilution), and fixed cells were incubated for 4 hours. Cells were then rinsed with PBS and subsequently incubated with rhodamine- or fluorescein-isothiocyanateconjugated secondary antibody (1:100 dilution) for 2 hours. Coverslips were rinsed with PBS and mounted on slide glasses using Gel/Mount (Biomeda Corp., Foster City, CA). When hGFAP-expressing cells were double labeled, an additional primary antibody was included in the diluted hGFAP-specific antibody solution, and the appropriate fluorochrome-conjugated secondary antibody was used. Primary antibodies used for double la- 

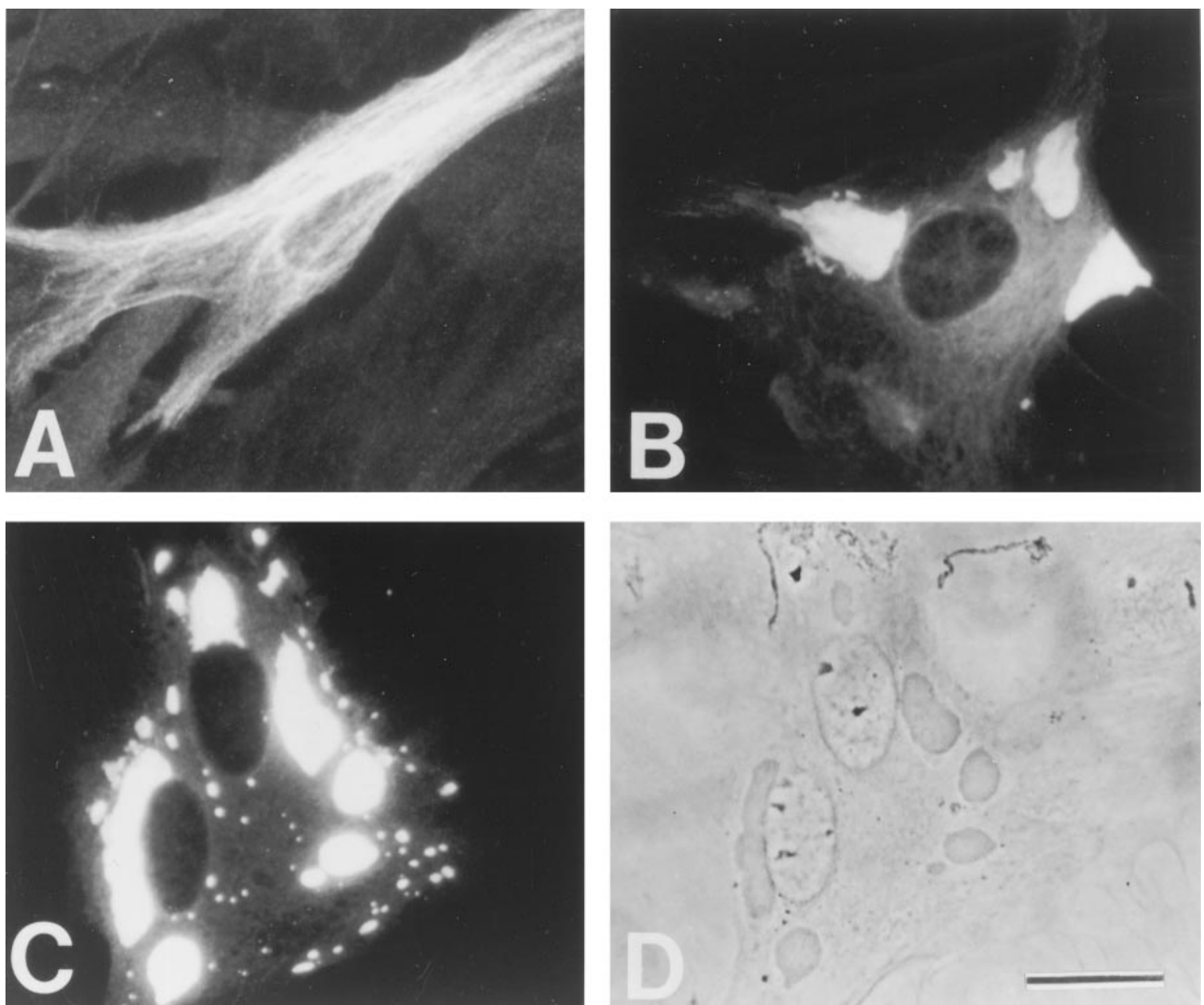

Figure 1. Filamentous and inclusion forms of hGFAP in mouse astrocytes transfected with RSVi-hGF. Mouse astrocytes were transfected with a hGFAP expression vector, RSVi-hGF, and stained with the anti-human GFAP-specific antibody 2 days after transfection. Astrocytes showing three different types of hGFAP organization are astrocytes showing filamentous hGFAP but no inclusion (A), co-existence of filaments and inclusions of hGFAP (B), and hGFAP inclusions without filaments (C). D: Phase-contrast image of C. Bar, $20 \mu \mathrm{m}$

beling of hGFAP-expressing cells were anti-rat $\alpha$ B-crystallin rabbit serum (CM2), ${ }^{6}$ anti-hsp25 (mouse homologue of hsp27) rabbit serum (StressGen Biotechnologies Corp., Victoria BC, Canada), anti-hsp70 rabbit serum (StressGen Biotechnologies), anti-ubiquitin rabbit serum
(StressGen Biotechnologies), anti- $\beta$-tubulin mouse monoclonal antibody (3F3-G2, ICN Biomedicals, Costa Mesa, CA), anti-vimentin mouse monoclonal antibody (VIM13.2, Sigma Chemical Co., St. Louis, MO), and anti$\beta$-Gal mouse antibody (Promega). To examine the orga-

Table 1. Organization of Vector-Derived hGFAP in Mouse Cultured Astrocytes, C6 Glioma, NIH3T3, and U251 Astrocytoma

\begin{tabular}{|c|c|c|c|}
\hline & \multicolumn{3}{|c|}{$\%$ Total transfected cells } \\
\hline & $\begin{array}{l}\text { Inclusions (+), } \\
\text { filamentous (-) }\end{array}$ & $\begin{array}{l}\text { Inclusions }(+) \\
\text { filamentous }(+)\end{array}$ & $\begin{array}{l}\text { Inclusions ( }(-) \text {, } \\
\text { filamentous }(+)\end{array}$ \\
\hline \multicolumn{4}{|c|}{ Mouse astrocytes } \\
\hline 2 days (4) & $11.9 \pm 3.6$ & $50.3 \pm 3.9$ & $37.9 \pm 2.5$ \\
\hline 7 days (3) & $9.0 \pm 1.4$ & $63.1 \pm 1.8$ & $27.9 \pm 0.6$ \\
\hline 14 days (3) & $15.7 \pm 1.9$ & $52.4 \pm 5.4$ & $31.9 \pm 3.7$ \\
\hline C6 (5) & $28.4 \pm 3.5$ & $46.1 \pm 3.0$ & $25.4 \pm 3.7$ \\
\hline NIH3T3 (4) & $3.0 \pm 0.9$ & $22.5 \pm 3.8$ & $74.5 \pm 3.9$ \\
\hline U251 (3) & $7.4 \pm 1.1$ & $25.2 \pm 4.1$ & $67.1 \pm 4.7$ \\
\hline
\end{tabular}

Cells were transfected with RSVi-hGF as described in Materials and Methods. The transfected mouse cultured astrocytes were fixed and stained with an anti-hGFAP-specific antibody 2, 7, and 14 days after the transfection. C6, NIH3T3, and U251 were stained 2 days after transfection. The organization of hGFAP was observed by epifluorescence light microscopy. In each experiment, more than 60 transfected cells were observed. The transfected cells are classified into three types: cells with hGFAP inclusions and no filaments (inclusion(+)/filamentous $(-)$ ), with inclusion and filaments (inclusion(+)/filamentous(+)), and with filaments and no inclusions (inclusion(-)/filamentous(+)). The percentages of each type are expressed as percentages of the total hGFAP-expressing cells. Results are means \pm SEM. Numbers of independent experiments are given in parentheses. 

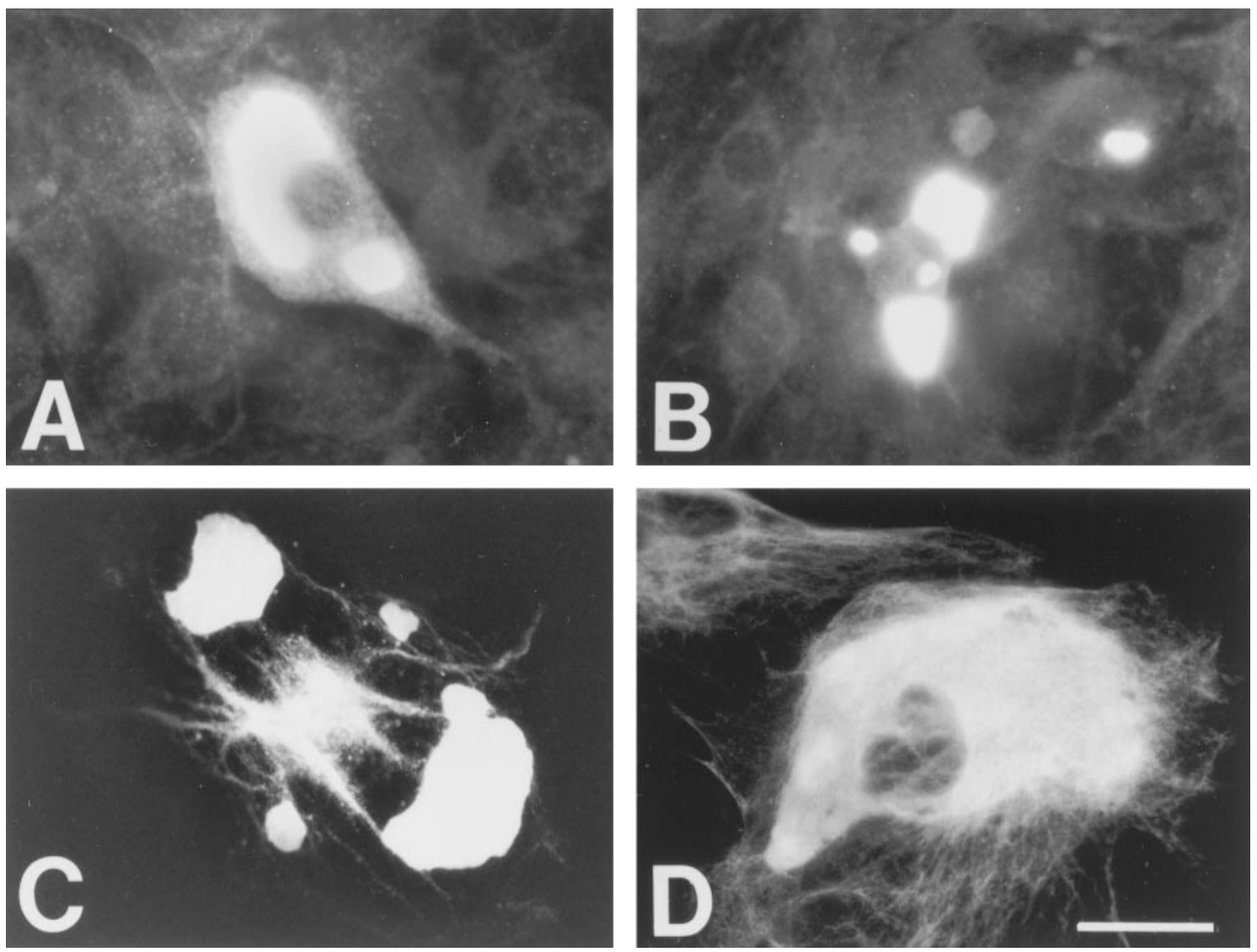

Figure 2. GFAP inclusions in NIH3T3, C6 glioma, U251 astrocytoma, and mouse astrocytes. NIH3T3 (A), C6 (B), and U251 (C) were transfected with RSV-hGF and stained with the anti-hGFAP specific antibody 2 days after the transfection. Mouse cultured astrocytes were transfected with mouse GFAP expression vector RSVi-mGF and stained with the pan-species anti-GFAP rabbit serum 2 days after the transfection (D). Bar, $20 \mu \mathrm{m}$.

nization of exogenous mouse GFAP, mouse astrocytes co-transfected with RSVi-mGF and pSV $\beta$-Gal were double labeled with a pan-species anti-GFAP rabbit serum $(A L D 10)^{28}$ and the anti- $\beta$-Gal antibody. GFAP organization of the $\beta$-Gal-expressing cells was then observed. Preabsorbed anti- $\alpha$ B-crystallin rabbit serum was prepared by incubating the serum with bovine lens $\alpha$-crystallin (Sigma; $12.5 \mu \mathrm{g}$ of $\alpha$-crystallin per $1 \mu \mathrm{l}$ of the antiserum) for 16 hours at $4^{\circ} \mathrm{C}$.

\section{Electron Microscopy}

One day before transfection, astrocytes were plated on 35-mm culture dishes, and co-transfection with hGFAP and $\beta$-Gal was made as described. Two days after the transfection, cells were fixed with $2.5 \%$ glutaraldehyde and $0.5 \%$ paraformaldehyde in PBS for 20 minutes. Transfected astrocytes were identified by X-Gal staining. At this point, those cells that contained inclusions were clearly visible. After the X-Gal staining, the cells were post-fixed with $1 \%$ osmium tetroxide in PBS. The cells were dehydrated through a graded series of ethanol washes, infiltrated, and embedded in epoxy resin. After the resin had solidified, the plastic culture dish was broken up to release the resin containing the embedded cells. X-Gal-stained cells that contained inclusions were selected under a light microscope. The resin containing the transfected cells was blocked and mounted onto blank sectioning stubs. The specimens were sectioned with a Diatome diamond knife on a Sorvall model MT7000 ultramicrotome. Silver and gray interference colored sections were collected onto uncoated 200- and 300-mesh copper grids. The sections were stained with uranyl acetate and lead citrate and viewed with a JEOL model 1200EX transmission electron microscope operating at $80 \mathrm{kV}$.

\section{Results}

\section{hGFAP Forms Intracytoplasmic Inclusions in Astrocytes}

hGFAP expressed in mouse astrocytes after transfection was organized in two distinct patterns. In some cells, hGFAP took on a filamentous pattern, identical to the endogenous IF network (Figure 1A). In other cells, however, the hGFAP was organized into one or more discrete inclusions, separate from the IF network (Figure 1, B and C). Other cells showed both the filamentous and inclusion patterns simultaneously. The inclusions varied in their sizes, shapes, and numbers, although all were cytoplas- 

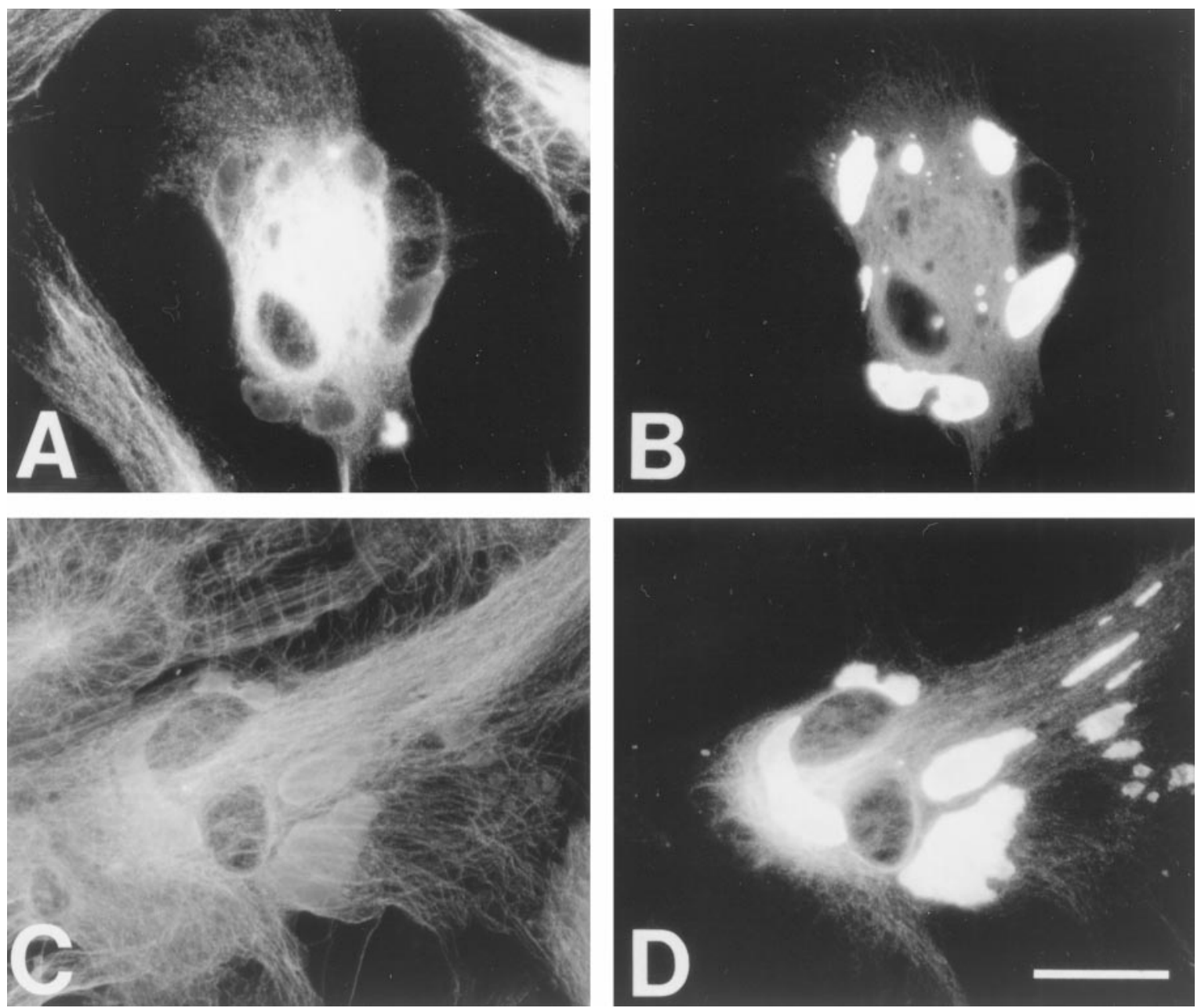

Figure 3. Vimentin and microtubule networks in RSVi-hGF transfected mouse astrocytes. Two days after the transfection with RSVi-hGF, organizations of microtubule and vimentin were observed. A) Vimentin staining; C: $\beta$-Tubulin staining; B and D: hGFAP staining of the same fields corresponding to A and C, respectively. Bar, $20 \mu \mathrm{m}$

mic and showed sharp, rounded borders. Some transfected cells contained one large inclusion, usually around the nucleus, whereas other cells contained many small inclusions scattered throughout the cytoplasm. Inclusions were observed as dark bodies under phase-contrast microscopy (Figure 1D). Treatment of cells with $0.2 \%$ NP-40 before fixation did not diminish the hGFAP inclusions, indicating that they are composed of detergent-insoluble, polymerized GFAP (see also electron microscopy, below). The inclusions appeared to be metabolically stable, as they were observed for at least 14 days after the transfection, and during that time, the percentage of transfected cells that bore inclusions did not change (Table 1).

The formation of hGFAP inclusions did not appear to be cell-type or species specific, as they were formed in NIH3T3, C6 rat glioma, and U251 human astrocytoma cells (Figure 2, A-C). However, the percentages of transfected cells that contained inclusions were small in NIH3T3 and U251 cells (Table 1). The formation of inclusions did not appear to be specific for hGFAP. Transfection with a mouse GFAP expression vector, RSVi-mGF, induced cytoplasmic inclusions in mouse astrocytes (Figure 2D) and NIH3T3 cells.

To determine whether the endogenous IF network was disrupted in the inclusion-bearing astrocytes, we co-labeled with antibodies for hGFAP and vimentin (as the IF system in the cultured astrocytes contains both GFAP and vimentin, which co-polymerize). The vimentin network appeared normal, well spread, and indistinguishable from that of nontransfected astrocytes (Figure 3, A and B). Vimentin was not found associated with the inclusions. Similarly, co-immunostaining with a $\beta$-tubulin antibody showed that the microtubule network was not disrupted and that tubulin was not found in the inclusions (Figure 3, C and D).

Electron microscopic observations of the transfected astrocytes showed that the inclusions were uniform structures that excluded all organelles (Figure 4). Individual 10-nm filaments were discernible but were not organized in any systematic way, such as bundles composed of parallel filaments, indicating a random organization. Some, but not all, of the inclusions appeared continuous with bundles of IFs (Figure 4B). 

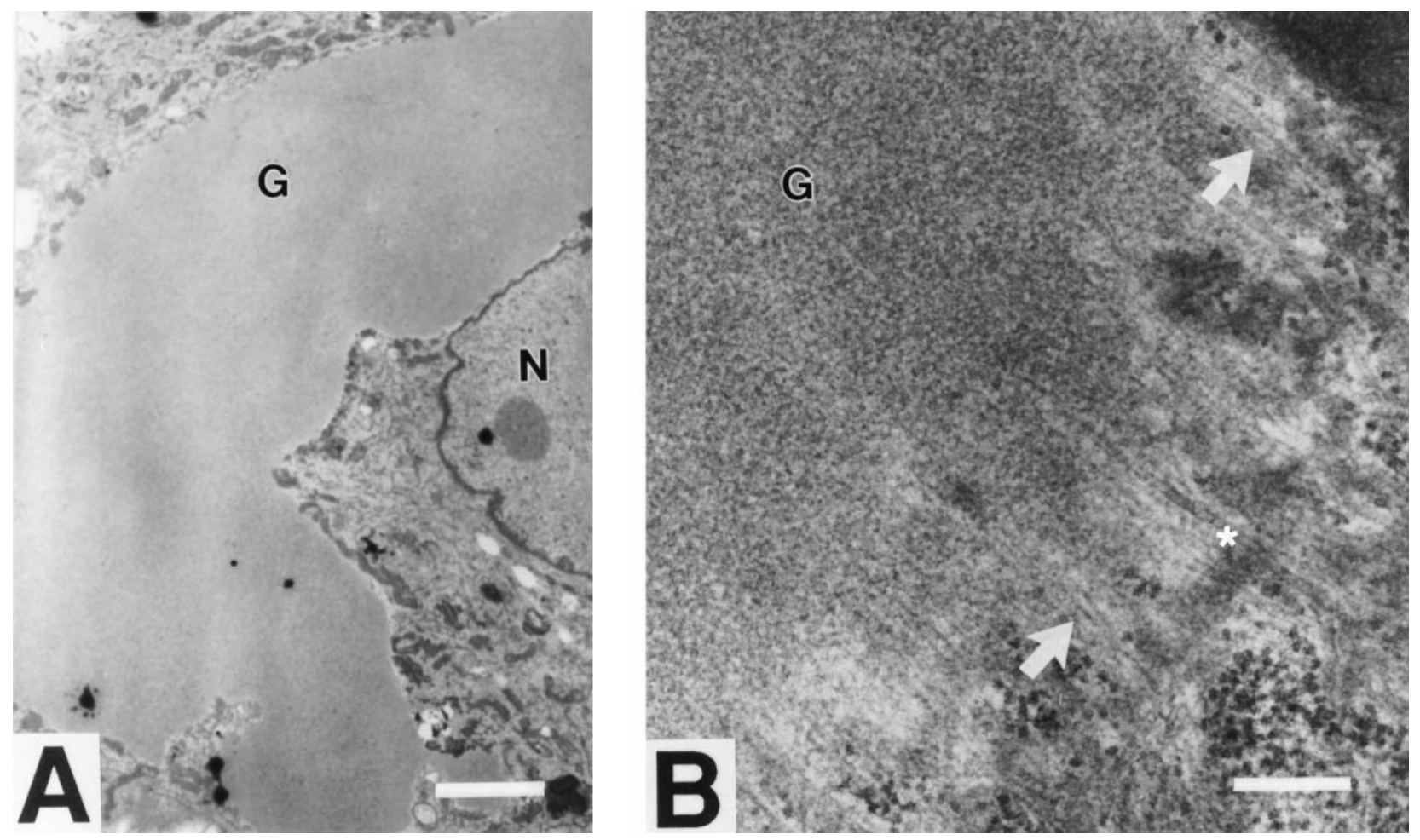

Figure 4. Electron microscopic observation of hGFAP inclusions in mouse astrocytes. Two days after the transfection with RSVi-hGF, astrocytes were fixed, stained by X-Gal, and embedded in epoxy resin. A: A hGFAP inclusion in mouse cultured astrocytes. G, hGFAP inclusion; N, nucleus; bar, $4 \mu \mathrm{m}$. B: Arrows indicate 10-nm filaments associated with the inclusion $(\mathrm{G})$; *microtubules. Bar, $0.2 \mu \mathrm{m}$

\section{$\alpha B$-Crystallin Disaggregates hGFAP Inclusions}

$\alpha \mathrm{B}$-crystallin is expressed at low levels in astrocytes under non-stress conditions. ${ }^{6}$ Most of the $\alpha$ B-crystallin is soluble and cytoplasmic, but a small proportion is tightly associated with the cytoskeleton, notably IFs. ${ }^{14}$ Immunocytochemical staining of astrocytes transfected with the hGFAP vector and then treated with NP-40 before fixation showed a positive signal for $\alpha \mathrm{B}$-crystallin associated with the hGFAP inclusions (Figure 5, A and B). The $\alpha$ B-crystallin staining of inclusions was not visualized in controls omitting primary antibody or with primary antibody preabsorbed with bovine lens $\alpha$ B-crystallin (data not shown). hGFAP inclusions also contained hsp25 (Figure 5, C and D), but we did not see positive reactions with antibodies to hsp70 or ubiquitin (not shown). $\alpha$ B-crystallin and hsp27 signals were also noted over the nucleus (Figure 5, $\mathrm{A}$ and $\mathrm{C}$ ), as noted previously for $\alpha \mathrm{B}$-crystallin, ${ }^{14}$ although what these proteins associate with is not known.

We then increased the levels of $\alpha \mathrm{B}$-crystallin in mouse astrocytes by infection with the $\alpha$ B-crystallin-expressing adenovirus vector $\alpha \mathrm{BSAD}$. Although the cultured astrocytes express low levels of $\alpha \mathrm{B}$-crystallin and the antibody does not discriminate between the endogenous mouse $\alpha \mathrm{B}$-crystallin and the (exogenous) rat $\alpha \mathrm{B}$-crystallin introduced by the vector, the infected cells clearly showed a far brighter signal (Figure 6C). Adenovirus infection and expression was efficient, with $30 \%$ to $50 \%$ of the astrocytes showing high levels of $\alpha \mathrm{B}$-crystallin after infection. Western blotting of astrocyte cultures infected with the $\alpha \mathrm{BSAD}$ show dramatically increased levels $\alpha \mathrm{B}$-crystallin, but levels that are similar to those that the astrocytes themselves accumulate after oxidative or thermal stress (MW Head, L Hurwitz, KB Kegel, and JE Goldman, submitted). Thus, the adenoviral gene transfer does not increase $\alpha \mathrm{B}$-crystallin levels above a range observed in stress conditions.

To examine the effects of $\alpha \mathrm{B}$-crystallin on the formation and maintenance of the GFAP inclusions, we performed two sets of experiments. In the first, astrocytes were initially transfected with the hGFAP vector to generate inclusions. Three days after transfection, levels of $\alpha \mathrm{B}$ crystallin were increased by infecting the cultures with $\alpha \mathrm{BSAD}$. We then examined those cells that contained both hGFAP and increased $\alpha \mathrm{B}$-crystallin and compared them with cultures that had not been exposed to the adenovirus. In controls, $\sim 70 \%$ of the hGFAP-expressing cells contained inclusions, whereas in the $\alpha \mathrm{B}$-crystallinadenovirus infected cells, only 30\% contained inclusions, with the remaining $70 \%$ displaying a filamentous pattern (Table 2). An additional decrease in the proportion of inclusion-bearing cells was not found 7 days after the $\alpha \mathrm{B}$-crystallin adenovirus infection. In the second set of experiments, astrocytes were first infected with $\alpha \mathrm{BSAD}$ and then, 3 days later, transfected with the hGFAP vector. The proportion of astrocytes containing inclusions was also substantially decreased compared with controls ( $\mathrm{Ta}$ ble 2). As an additional control, we substituted a $\beta$-Gal adenovirus, $\beta$-GalAD, for the $\alpha \mathrm{BSAD}$ and found no de- 

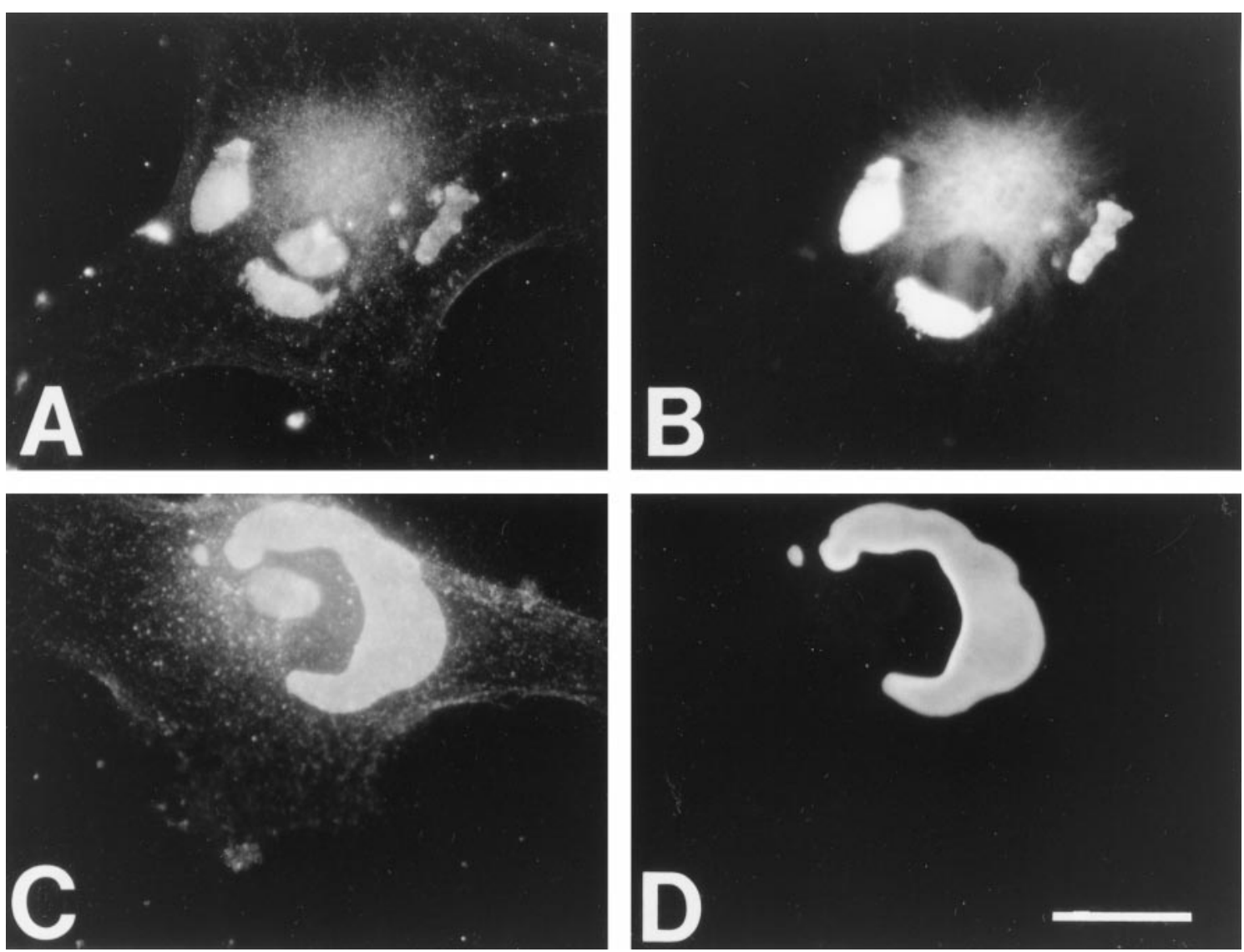

Figure 5. Accumulation of $\alpha$ B-crystallin and hsp25 in hGFAP inclusions. Mouse astrocytes were transfected with RSVi-hGF, and immunohistochemical studies were performed 2 days after the transfection. To remove soluble, cytoplasmic $\alpha$ B-crystallin, cells were treated with $0.2 \%$ NP- 40 containing PBS for 2 minutes before fixation. Localization of detergent-insoluble $\alpha \mathrm{B}$-crystallin and hsp25 in hGFAP-expressing cells was examined by double labeling with anti-hGFAP specific antibody. A: $\alpha$ B-crystallin staining; C: hsp25 staining; B and D: hGFAP staining of the same fields corresponding to A and C, respectively. Bar, $20 \mu \mathrm{m}$.

crease in the proportion of hGFAP-expressing astrocytes that contained inclusions. Thus, adenovirus infection per se does not alter IF organization and inclusion formation.

\section{Discussion}

\section{Possible Mechanisms for Inclusion Formation}

In this study, hGFAP introduced into mouse astrocytes produced two distinct types of cytoskeletal structures, filamentous and inclusion forms (Figure 1). Before our experiments, exogenous GFAP had been found to be expressed in several cell types, ${ }^{26,29-31}$ but in all cases, the GFAP polymerized into the endogenous IF network, and inclusions were not reported. We found that the susceptibility of hGFAP inclusion formation varied among different cell types (Table 1). Thus, in addition to differences in gene transfer methods, the types of host cells may explain the different results from the previous studies.

The discrete GFAP inclusions are reminiscent of the IF aggregation produced by microtubule disrupting agents. ${ }^{32-34}$ IF spreading is likely to be maintained by a mutual association between IFs and microtubules via linking proteins. The nature of these linking proteins is not clear, but they may include the so-called IF-associated proteins (IFAPs) ${ }^{35-38}$ or members of the kinesin family of molecular motors. ${ }^{39}$ We noted, however, that the endogenous networks of microtubules in the GFAP inclusionbearing astrocytes appeared to be maintained normally (Figure 3) and, furthermore, that in some astrocytes, the added GFAP was incorporated into a spread IF network. In other cells, both inclusions and filamentous forms coexisted (Figure 1). These results indicate that the ability to organize the endogenous IF network was not impaired by the inclusion formation. Thus, one possible mechanism for inclusion formation is that the amount of the added GFAP was excessive in relation to microtubules and IFAPs and could not be maintained in a spread form, resorting to the default, inclusion form. The proportion of cells that formed inclusions varied with the cell type, being lowest in NIH3T3 cells and highest in C6 cells (Table 1). This may reflect higher ratios of microtubules to IFs in the 3T3 cells than in astrocytes, but additional studies should be performed before a clear conclusion can be drawn.

Another possible mechanism for inclusion formation is that they result from a defective interaction between the endogenous mouse IF proteins and the human GFAP. In fact, despite a high homology ( $90 \%$ identity) as a whole, ${ }^{40}$ the amino acid sequence of hGFAP shows the most difference from mouse GFAP in the amino-terminal head domain, which is responsible for assembly charac- 

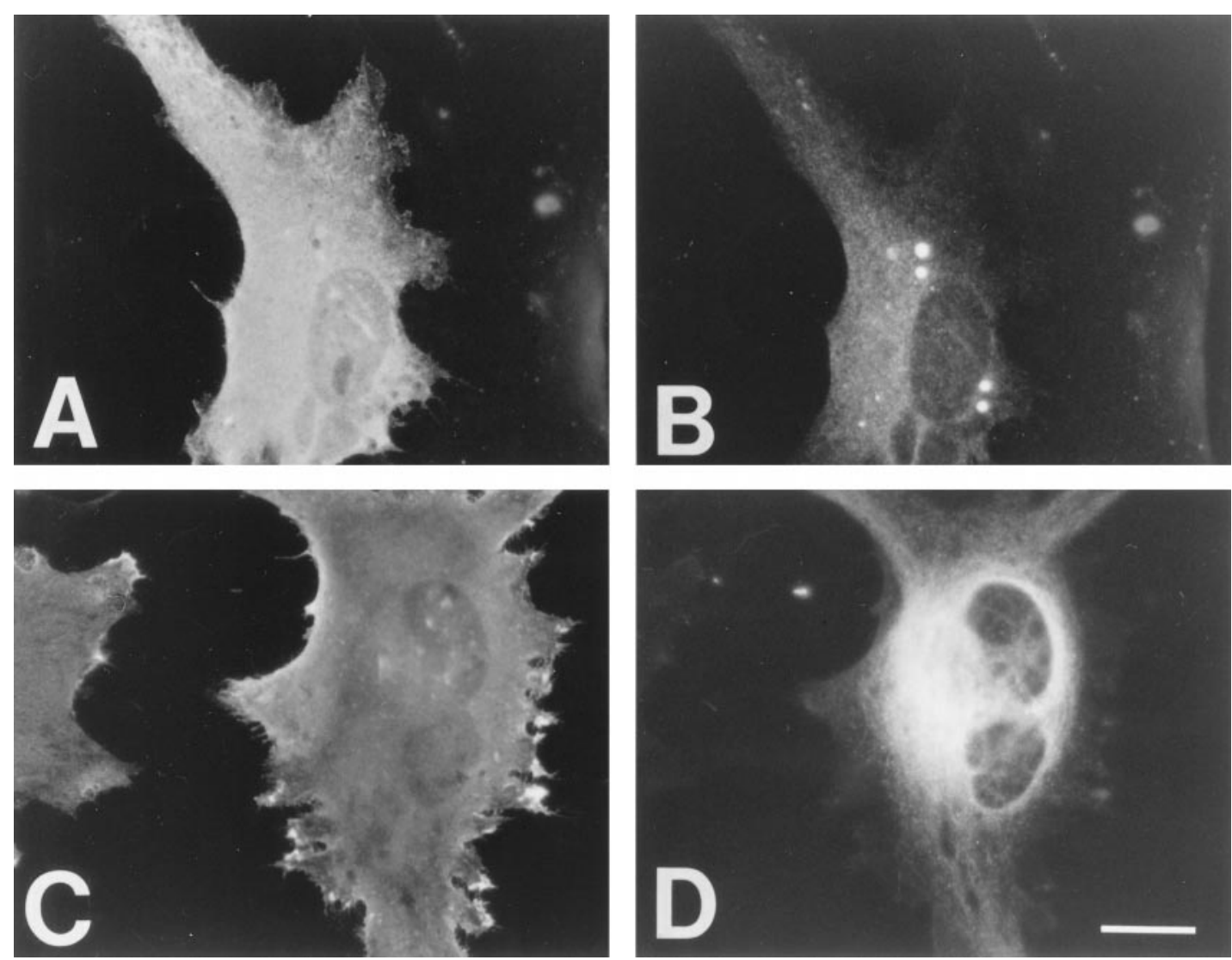

Figure 6. Expression of $\alpha \mathrm{B}$-crystallin and $\beta$-Gal in RSV-hGF transfected mouse astrocytes. Two days after transfection with RSVi-hGF, astrocytes were infected with either $\alpha$ B-crystallin or $\beta$-Gal expression adenovirus vector. Organization of hGFAP was observed 3 days after the adenovirus infection. Representative results are presented. A and B: $\beta$-Gal expression. A cell expressing $\beta$-Gal (A) shows small hGFAP inclusions (B). $\mathrm{C}$ and D: $\alpha \mathrm{B}$-crystallin expression. An exogenous $\alpha$ B-crystallin-expressing cell (C) shows filamentous hGFAP (D). Bar, $20 \mu \mathrm{m}$.

teristics of GFAP proteins. ${ }^{26,41}$ However, the formation of inclusions did not depend on differences in species, as inclusions were present after adding mouse GFAP to mouse astrocytes (Figure 2D). Therefore, it is likely thatinclusions were induced by an excess accumulation of GFAP molecules in the cells per se, rather than by differences in the GFAP protein sequences among species.

\section{$\alpha B$-Crystallin Disaggregates IF Inclusions}

We had initially thought that the introduction of $\alpha \mathrm{B}$-crystallin by a recombinant adenovirus vector to the GFAP inclusion-bearing astrocytes might result in RF formation. This idea was predicated on a quantitative model in which high levels of small hsps would deposit on IF

Table 2. Effects of Adenovirus-Mediated $\alpha$ B-Crystallin and $\beta$-Gal Expression on hGFAP Inclusions in Mouse Cultured Astrocytes

\begin{tabular}{|c|c|c|c|}
\hline \multirow[b]{2}{*}{ Adenovirus infection } & \multicolumn{3}{|c|}{ Inclusion-bearing cells (\% total hGFAP-expressing cells) } \\
\hline & None & $\beta$-Gal & $\alpha \mathrm{B}$-crystallin \\
\hline \multicolumn{4}{|l|}{ Exp. 1: Adenovirus infection after inclusion formation } \\
\hline 3 days $(5)$ & $73.2 \pm 3.1$ & $70.6 \pm 1.9$ & $34.3 \pm 1.2^{*}$ \\
\hline 7 days (4) & $68.5 \pm 4.7$ & $69.4 \pm 1.8$ & $32.4 \pm 3.7^{\dagger}$ \\
\hline \multicolumn{4}{|l|}{ Exp. 2: Adenovirus infection before inclusion formation } \\
\hline 2 days $(3)$ & $76.5 \pm 3.0$ & $73.4 \pm 1.3$ & $46.1 \pm 1.6^{\dagger}$ \\
\hline
\end{tabular}

For experiment (Exp.) 1, cultured astrocytes were transfected with RSVi-hGF. Two days after the transfection, the cells were infected with either $\beta$ Gal or $\alpha \mathrm{B}$-crystallin gene carrying adenovirus. Organization of hGFAP in astrocytes expressing $\beta$-Gal or exogenous $\alpha$ B-crystallin was observed 3 and 7 days after the adenovirus infection. In each experiment, more than 100 cells were observed. For experiment 2, astrocytes were first infected with the adenovirus vectors. Three days after the adenovirus infection, the cells were transfected with RSVi-hGF. Organization of hGFAP was observed 2 days after the transfection. In each experiment, more than 50 cells were observed. Irrespective of the size and number of inclusions, a cell with visible inclusions was scored as inclusion-bearing cell. The numbers of inclusion-bearing cells are expressed as the percentage of total astrocytes expressing hGFAP. Results are mean \pm SEM, and statistical analysis was made by Student's $t$-test. Numbers of independent experiments are given in parentheses.

${ }^{*} P<0.001$ versus none.

${ }^{\dagger} P<0.01$ versus none. 
bundles. Indeed, it might be possible to generate RFs by this method, but if so, we have not yet reached a critical threshold for small hsp aggregation on the IFs. However, instead of forming RFs, the introduction of $\alpha \mathrm{B}$-crystallin markedly decreased the percentage of astrocytes that contained inclusions, apparently converting the hGFAP from an aggregate form to a normal filamentous organization (Table 2). We suggest that this conversion is due to a disaggregation or debundling of polymerized IFs and does not occur through a depolymerization-repolymerization cycle. The reason for this inference is that overexpression of $\alpha \mathrm{B}$-crystallin in normal astrocytes (without hGFAP transfection) had no effect on the detergent solubility of the endogenous GFAP (MW Head, L Hurwitz, KB Kegel, and JE Goldman, submitted). Although $\alpha \mathrm{B}$-crystallin inhibits GFAP polymerization in vitro, ${ }^{13}$ our observations suggest that the effects of $\alpha \mathrm{B}$-crystallin on IF states in vivo has more to do with organization of IFs than with the polymerization state. For the experiments reported here, however, the transfection efficiency with hGFAP was too low to allow us to perform biochemical determinations of hGFAP polymerization states after infection with the $\alpha \mathrm{B}$-crystallin adenovirus.

The idea that $\alpha \mathrm{B}$-crystallin in some way organizes IFs is strongly supported by a recent finding of Vicart et al on a desmin-related myopathy (DRM), ${ }^{42}$ a disease characterized by formation of desmin aggregates in muscle cells. They found a mutation of the $\alpha \mathrm{B}$-crystallin gene in DRM patients and showed that introduction of the mutated $\alpha \mathrm{B}$-crystallin induced cytoplasmic inclusions composed of desmin and $\alpha \mathrm{B}$-crystallin in muscle cell lines. $\alpha \mathrm{B}$-crystallin is normally associated with IFs in several cell types ${ }^{12-14}$ and therefore might act as an IFAP, although it is not clear whether this is a direct interaction or whether it is mediated by other proteins. A study on fibroblasts from patients of giant axonal neuropathy, a disease characterized by IF-containing inclusion formation in various types of cells, suggested that some inducible protein factors convert the IF aggregates to filamentous structures. ${ }^{43} \alpha$ B-crystallin may be one of such inducible factors.

In a variety of neuropathologies it is common to see hypertrophic astrocytes with accumulated IFs in cell body and processes. The expression of $\alpha \mathrm{B}$-crystallin in astrocytes is also increased in many pathological conditions. ${ }^{4-46}$ The increased $\alpha \mathrm{B}$-crystallin and IF proteins result in formation of RFs in astrocytes of Alexander disease, chronic glial scars, and low-grade fibrillary astrocytomas. ${ }^{18-20}$ Observations in the hGFAP-overexpressing mouse indicate directly that the accumulation of IFs up-regulates small hsp expression (see Introduction). Thus, the present results suggest that one of the functions of $\alpha \mathrm{B}$-crystallin is to assist in maintaining the IF network and, if the network is disrupted, to play a role in rearrangement to a normal state.

\section{Acknowledgments}

We thank Dr. Ronald Liem for expression vectors, Dr. Michael Brenner for the mouse GFAP cDNA clone, and
Drs. Jody Martin and Wolfgang Dillmann for the adenovirus vectors. We also thank Kristy Brown for the electron microscopy and Drs. Mark Head, Ronald Liem, and Michael Shelanski for their many helpful discussions.

\section{References}

1. Iwaki T, Kume-Iwaki A, Liem RKH, Goldman J: $\alpha$ B-crystallin is expressed in non-lenticular tissue and accumulates in Alexander's disease. Cell 1989, 57:71-78

2. Bhat SP, Nagineni $\mathrm{CN}$ : $\alpha \mathrm{B}$ subunit of lens-specific protein $\alpha$-crystallin is present in other ocular and non-ocular tissue. Biochem Biophys Res Commun 1989, 158:319-325

3. Dubin RA, Wawrousek EF, Piatigorsky J: Expression of the murine $\alpha \mathrm{B}$-crystallin gene is not restricted to the lens. Mol Cell Biol 1989, 9:1083-1091

4. Aoyama A, Frohli E, Schafere R, Klemenz R: $\alpha$ B-crystallin expression in mouse NIH3T3 fibroblasts: glucocorticoid responsiveness and involvement in thermal protection. Mol Cell Biol 1993, 13:1824-1835

5. Klemenz R, Andres A-C, Frohli E, Schafer R, Aoyama A: Expression of the murine small heat shock proteins hsp25 and $\alpha \mathrm{B}$ crystallin in the absence of stress. J Cell Biol 1993, 120:639-645

6. Head MW, Corbin E, Goldman JE: Coordinate and independent regulation of $\alpha \mathrm{B}$-crystallin and HSP27 expression in response to physiological stress. J Cell Physiol 1994, 159:41-50

7. Horwitz J: $\alpha$-Crystallin can function as a molecular chaperone. Proc Natl Acad Sci USA 1992, 89:10449-10453

8. Iwaki T, Iwaki A, Tateishi J, Goldman JE: Sense and antisense modification of glial $\alpha$ B-crystallin production results in alterations of stress fiber formation and thermoresistance. J Cell Biol 1994, 125:13851393

9. Kegel KB, Iwaki A, Iwaki T, Goldman JE: $\alpha$ B-crystallin protects glia cells from hypertonic stress. Am J Physiol 1996, 270:C903-C909

10. Liang P, MacRae TH: Molecular chaperones and the cytoskeleton. J Cell Sci 1997, 110:1431-1440

11. Wang K, Spector A: $\alpha$-Crystallin stabilizes actin filaments and prevents cytochalasin-induced depolymerization in a phosphorylationdependent manner. Eur J Biochem 1996, 242:56-66

12. Bennardini F, Wrzosek A, Chiesi M: $\alpha$ B-crystallin in cardiac tissue: association with actin and desmin filaments. Circ Res 1992, 71:288294

13. Nicholl ID, Quinlan RA: Chaperone activity of $\alpha$-crystallins modulates intermediate filament assembly. EMBO J 1994, 13:945-953

14. Wisniewski T, Goldman JE: $\alpha \mathrm{B}$-crystallin is associated with intermediate filaments in astrocytoma cells. Neurochem Res 1998, 23:385392

15. Hazan R, Denk H, Franke WW, Lackinger E, Schiller DL: Change of cytokeratin organization during development of Mallory bodies as revealed by a monoclonal antibody. Lab Invest 1986, 54:543-553

16. Bergeron C, Dickson DW, Pollanen MS: Pathology and biology of the Lewy body. J Neuropathol Exp Neurol 1993, 52:183-191

17. Lowe J, Blanchard A, Morrell K, Lennox G, Reynolds L, Billett M, Landon M, Mayer RJ: Ubiquitin is a common factor in intermediate filament inclusion bodies of diverse type in man, including those of Parkinson's disease, Pick's disease, and Alzheimer's disease, as well as Rosenthal fibers in cerebellar astrocytomas, cytoplasmic bodies in muscle, and Mallory bodies in alcoholic liver disease. J Pathol 1988, 155:9-15

18. Grcevic N, Yates PO: Rosenthal fibers in tumours of the central nervous system. J Pathol Bacteriol 1957, 73:467-472

19. Herndon RM, Rubinstein LJ, Freeman JM: Light and electron microscopic observations on Rosenthal fibers in Alexander's disease and in multiple sclerosis. J Neuropathol Exp Neurol 1970, 29:524-551

20. Chin SS-M, Goldman JE: Glial inclusions in CNS degenerative diseases. J Neuropathol Exp Neurol 1996, 55:499-508

21. Tomokane N, Iwaki T, Tateishi J, Iwaki A, Goldman JE: Rosentha fibers share epitopes with $\alpha$ B-crystallin, glial fibrillary acidic protein and ubiquitin, but not with vimentin: immunoelectron microscopy with colloidal gold. Am J Pathol 1991, 138:875-885

22. Lowe J, McDermott H, Pike I, Spendlove I, Landon M, Mayer J: $\alpha \mathrm{B}$-crystallin expression in non-lenticular tissues and selective pres- 
ence in ubiquitinated inclusion bodies in human disease. $J$ Pathol 1992, 166:61-68

23. Kato S, Hirano A, Umehara T, Kato M, Herz R, Ohama E: Comparative immunohistochemical study on the expression of $\alpha \mathrm{B}$-crystallin, ubiquitin and stress-response protein 27 in ballooned neurons in various disorders. Neuropathol Appl Neurobiol 1992, 18:335-340

24. Messing A, Head MW, Galles K, Galbreath EJ, Goldman JE, Brenner M: Fatal encephalopathy with astrocyte inclusions in GFAP transgenic mice. Am J Pathol 1998, 152:391-398

25. Eng LF, Lee YL, Kwan H, Brenner M, Messing A: Astrocytes cultured from transgenic mice carrying the added human glial fibrillary acidic protein gene contain Rosenthal fibers. J Neurosci Res 1998, 53:353360

26. Chen W-J, Liem RKH: The endless story of the glial fibrillary acidic protein. J Cell Sci 1994, 107:2299-2311

27. Martin JD, Mestril R, Hilal-Dandan R, Brunton LL, Dillmann WH: Small heat shock proteins and protection against ischemic injury in cardiac myocytes.. Circulation 1997, 96:4343-4348

28. Chiu FC, Goldman JE: Synthesis and turnover of cytoskeletal proteins in cultured astrocytes. J Neurochem 1984, 42:166-174

29. Toda M, Miura M, Asou H, Toya S, Ueyama K: Cell growth suppression of astrocytoma C6 cells by glial fibrillary acidic protein cDNA transfection. J Neurochem 1994, 63:1975-1978

30. Murakami M, Fukuyama, Hubbard S, Matsuzawa K, Dirks PB, Rutka $\mathrm{JT}$ : Inducible expression of glial fibrillary acidic protein in HT-1080 human fibrosarcoma cells. Cell Growth Differ 1996, 7:1697-1703

31. Rutka JT, Smith S-L: Transfection of human astrocytoma cells with glial fibrillary acidic protein complementary DNA: analysis of expression, proliferation, and tumorigenicity. Cancer Res 1993, 53:36243631

32. Forry-Schaudies S, Murry JM, Toyama Y, Holtzer H: Effects of colcemid and taxol on microtubules and intermediate filaments in chick embryo fibroblasts. Cell Motil Cytoskel 1986, 6:324-338

33. Geuens G, de Brabander M, Nuydens R, de Mey J: The interaction between microtubules and intermediate filaments in cultured cells treated with taxol and nocodazole. Cell Biol Int Rep 1983, 7:35-47

34. Blose SH, Meltzer DJ, Feramisco JR: $10 \mathrm{~nm}$ Filaments are induced to collapse in living cells microinjected with monoclonal and polyclonal antibodies against tubulin. J Cell Biol 1984, 98:847-858
35. Bloom GS, Vallee RB: Association of microtubule-associated protein 2 (MAP2) with microtubules and intermediate filaments in cultured brain cells. J Cell Biol 1983, 96:1523-1531

36. Lin JJ-C, Feramisco JR: Disruption of the in vitro distribution of the intermediate filaments in fibroblasts through the microinjection of a specific monoclonal antibody. Cell 1981, 24:185-193

37. Draberova E, Draber P: A microtubule-interacting protein involved in coalignment of vimentin intermediate filaments with microtubules. J Cell Biol 1993, 106:1263-1273

38. Foisner R, Wiche G: Intermediate filament-associated proteins. Curr Opin Cell Biol 1991, 3:75-81

39. Liao G, Gundersen GG: Kinesin is a candidate for cross-bridging microtubules and intermediate filaments: selective binding of kinesin to detyrosinated tubulin and vimentin. J Biol Chem 1998, 273:97979803

40. Brenner M, Lampel K, Nakatani Y, Mill J, Banner C, Mearow K, Dohadwala M, Lipsky R, Freese E: Characterization of human cDNA and genomic clone for glial fibrillary acidic protein. Brain Res 1990, 7:277-286

41. Ralton JE, Lu X, Hutcheson AM, Quinlan RA: Identification of two $\mathrm{N}$-terminal non- $\alpha$-helical domain motifs important in the assembly of glial acidic protein. J Cell Sci 1994, 107:1935-1948

42. Vicart P, Caron A, Guicheney P, Li Z, Prevost M-C, Faure A, Chateau D, Chapon F, Tome F, Dupret J-M, Paulin D, Fardeau M: A missense mutation in the $\alpha \mathrm{B}$-crystallin chaperone gene causes a desmin-related myopathy. Nature Genet 1998, 20:92-95

43. Klymkowsky MW, Plummer DJ: Giant axonal neuropathy: a conditional mutation affecting cytoskeletal organization. J Cell Biol 1985, 100:245-250

44. Iwaki T, Wisniewski T, Iwaki A, Corbin E, Tomokane N, Tateishi J, Goldman JE: Accumulation of $\alpha \mathrm{B}$-crystallin in central nervous system glia and neurons in pathological conditions. Am J Pathol 1992, 140: 345-356

45. Renkawek K, de Jong WW, Merck KB, Frenken CWGM, van Workum FPA, Bosman GJCGM: $\alpha$ B-crystallin is present in reactive glia in Creutzfeldt-Jakob disease. Acta Neuropathol 1992, 83:324-327

46. Renkawek K, Voorter CEM, Bosman GJCG, van Workum FPA, de Jong WW: Expression of $\alpha \mathrm{B}$-crystallin in Alzheimer's disease. Acta Neuropathol 1994, 878:155-160 